\title{
Erratum to: The roles of phosphoinositides in mammalian autophagy
}

Deok-Jin Jang ${ }^{1} \cdot$ Jin-A Lee ${ }^{2}$

Published online: 8 September 2016

(C) The Pharmaceutical Society of Korea 2016

Erratum to: Arch. Pharm. Res. (2016)

\section{9:1129-1136 \\ DOI 10.1007/s12272-016-0777-X}

We apologize that there is an error in Figs. 1 and 2 legends.

The online version of the original article can be found under doi:10.1007/s12272-016-0777-X.

\section{Jin-A Lee}

leeja@hnu.kr

1 Department of Applied Biology, College of Ecology and Environment, Kyungpook National University, Sangju, Republic of Korea

2 Department of Biological Sciences and Biotechnology, College of Life Sciences and Nanotechnology, Hannam University, Daejeon, Republic of Korea 